\title{
Auto-LPG (Liquefied Petroleum Gas) and its Health Outcomes: A Review
}

\author{
Vivien Fe F. Fadrilan-Camacho
}

Department of Environmental and Occupational Health, College of Public Health, University of the Philippines Manila

\begin{abstract}
The use of auto-LPG (Liquefied Petroleum Gas) has spread globally due to its economic and environmental advantages over gasoline and diesel. The growing popularity of auto-LPG in the country has been challenged by reported health complaints from its use instigating alarms among taxi drivers and passengers. This paper aims to review documented health outcomes of auto-LPG among drivers. Health outcomes of autoLPG are classified to inhalation effects and burns. Auto-LPG is expected to have inhalational effects such as headache, dizziness, dry throat, nausea and dry cough during prolonged exposure caused by leakage from faulty conversions. Fire and explosion causing significant burns were documented in relation to auto-LPG use. Cases of cold burns or frostbite were also reported. Human factors and technical malfunctions causing leakage were implicated on the reported adverse health events. Limited studies on auto-LPG and health outcomes require the development and use of objective assessments of health outcomes and presence of auto-LPG in the driver's environment to make relevant correlations. Regulations governing auto-LPG should be reviewed to formulate strategic interventions to promote health and safety of drivers as well as the passengers.
\end{abstract}

Key Words: auto-LPG, liquefied petroleum gas, propane, health outcomes

\section{Introduction}

The increased number of transport vehicles has been related to the growing problem of air pollution and climate change. Road transport vehicles are considered as the major source of air pollutants and climate-destabilizing greenhouse effects. Measures have been initiated to address these environmental issues that have a major impact on population health. Concerns for the political instability of oil-exporting countries leading to increased cost of fuel have also been raised. ${ }^{1}$ These concerns propelled for the utilization of alternative fuel such as auto-Liquefied Petroleum Gas (auto-LPG) in the transport industry.

Studies showed that emissions from auto-LPG vehicles contain lower carbon dioxide $\left(\mathrm{CO}_{2}\right)$, nitrogen oxides, sulfur oxides and particulates which make it a cleaner fuel than

\footnotetext{
Corresponding author: Vivien Fe F. Fadrilan-Camacho, MD, MPH, DPAFP Department of Environmental and Occupational Health College of Public Health

University of the Philippines Manila

625 Pedro Gil St., Ermita, Manila 1000 Philippines

Telephone: +639178288705/+639228848436

Email: doktora_bing@yahoo.com
}

gasoline and diesel., ${ }^{2,3}$ These properties of auto-LPG contribute to the world's environmental agenda of resolving poor air quality and global warming accelerated through the release of greenhouse gases. Economic benefit of auto-LPG includes $30-40 \%$ savings on fuel cost compared to gasoline and diesel. ${ }^{2,5,6}$ It is cheaper on a net fuel cost basis adjusting for energy content and consumption. ${ }^{7}$ With these environmental and economic advantages, the use of autoLPG has spread globally since its introduction in Europe in the 1940's. It is now considered as the third fuel of choice for motorists. ${ }^{8}$ The Department of Energy (DOE) promotes its Auto-LPG Program to diversify the country's fuel sources while contributing to solutions to air pollution caused by vehicular emissions. Its wide use has been promoted for its environmental benefits as early as 2002, three years after the passage of the Clean Air Act. ${ }^{9}$

The growing popularity of LPG fuel has been challenged by reported negative health effects among taxi drivers. The drivers reported health complaints such as headache, dizziness, dry throat, unusual fatigue and asthma since they started driving auto-LPG taxis. ${ }^{10}$ These reports instigated alarms among drivers and passengers with regard to the safety of auto-LPG. Limited information on its health effects has stalled appropriate and specific actions to address the concerns regarding auto-LPG use.

This paper aims to review documented data on autoLPG fuel and its health outcomes among drivers. It shall serve as an initial step towards research on objective assessments of health effects related to auto-LPG. It shall also provide baseline information for strategic interventions in the form of health policies to promote health and safety of the drivers as well as the passengers.

\section{Auto-LPG as a Fuel}

Auto-LPG was first used in the beginning of the 20th century but only at a limited scale. The oil crisis of 1973 made auto-LPG more popular when territories such as US and Canada tried to reduce their dependence on crude oil. In the 1990's, the increased demand of the fuel is driven by growing environmental concerns. ${ }^{2,11}$

Auto-LPG, also known as autogas, consists of a mixture of propane, butane and other simple hydrocarbons. ${ }^{12}$ It is derived either as a product from crude-oil refining or from natural-gas or oil production. At present, more than $60 \%$ of global auto-LPG supply comes from natural gas processing 
plants. ${ }^{8}$ Auto-LPG vapor is odorless, colorless, and heavier than air, so it will not disperse easily without wind or ventilation. It has a high ignition temperature compared to gasoline and diesel. Because of its cold temperature when it changes from liquid to gas, care must be exercised when refueling with auto-LPG to prevent cold burns. ${ }^{13}$

\section{Auto-LPG fuel Users}

There are more than 17.4 million auto-LPG vehicles around the world and over 57,000 refueling sites. The world's largest user of auto-LPG is Korea with 2.3 million auto-LPG vehicles on the road. It is also widely used in Turkey, Poland, Japan, Australia, Russian Federation, Italy, Mexico, Thailand and the USA. Taxis account for a large share of auto-LPG consumption in Korea and Japan. ${ }^{13}$ In the country, there were 19,052 auto-LPG taxis in 2011 which make up $52 \%$ of all taxis nationwide. ${ }^{9}$ Marketing strategies are being offered to the drivers by auto-LPG suppliers such as free meals or groceries for a minimum purchase of the fuel making it more appealing to drivers.

\section{LPG and the Environment}

Motorized transport makes a substantial contribution to the urban air pollution which in turn is responsible for 1.3 million deaths a year. ${ }^{14}$ With the rapid increase of use of vehicles, large amount of hydrocarbons and nitrogen oxides (NOx) are released to the atmosphere. This leads to the formation of ground-level ozone which has become a global source of pollution posing as a respiratory hazard. Air particulates from vehicular emissions aggravate respiratory and cardiovascular diseases. ${ }^{1,3}$ Motor vehicles have been an increasing source of emission of greenhouse gases such as carbon dioxide $\left(\mathrm{CO}_{2}\right)$, methane $\left(\mathrm{CH}_{4}\right)$ and nitrous oxide $\left(\mathrm{N}_{2} \mathrm{O}\right)$ as well as ozone precursor gases like carbon monoxide (CO), oxides of nitrogen (NOx) and non-methane volatile organic carbon (NMVOC). ${ }^{15}$ These gases particularly carbon dioxide accelerates global warming which has potential detrimental effects to the environment and human health.

Governments around the world encourage the utilization of alternative fuels such as auto-LPG to reduce urban air pollution. It is said to be cleaner than gasoline and diesel because it is composed of predominantly simple hydrocarbon compounds. It is free of lead and contains minimal amount of sulfur. Compared to vehicles on gasoline and diesel, auto-LPG vehicles produce at least $20 \%$ less $\mathrm{CO}_{2}$, $60 \%$ less CO, and 20\% less NOx. Studies showed that autoLPG vehicles have remarkable advantage in terms of vehicular emissions if the conversions are carried out by qualified technicians; with strict and appropriate maintenance program. . $^{3,4,16-18}$

\section{Auto-LPG and Health Outcomes}

It seemed like LPG fuel was the answer to the environmental and economic concerns in the transport as well as the energy sector. The global auto-LPG industry has promoted health advantages of LPG fuel due to its less emission levels compared to gasoline and diesel. Its lower emissions of air contaminants reduce potential pulmonary hazards which have significant impact on public health. ${ }^{3,6,7} \mathrm{~A}$ number of health-related events on the use of auto-LPG were reported and were found to be related to human errors and technical malfunctions. These health outcomes are classified into inhalation effects and burns.

\section{Inhalation Effects}

Auto-LPG is composed mainly of propane and the rest are butane and other simple hydrocarbons. It is a colorless and odorless gas. A pungent odorant is usually added so that it can be easily detected during leakage. Propane is considered as an asphyxiant. Exposure to high concentrations $(>10 \%)$ may cause dizziness. Exposure to atmospheres containing $8-10 \%$ or less oxygen will cause unconsciousness and eventually death. The current Occupational Safety and Health Administration (OSHA) standard for LPG is 1000 parts per million parts of air (ppm) averaged over an eight-hour work shift. 2,19

Inhalation effects of auto-LPG such as headache, dizziness and nausea due to $\mathrm{CO}$ exposure were documented in several studies done on LPG-fueled forklifts and warehouse workers. Investigations led to measures to control the hazard through ideal oxygen-fuel ratio, reasonable dilution or substitution with the less hazardous electric-powered forklifts. ${ }^{20}$ Reports of auto-LPG poisoning resulting to death due to LPG leakage were documented but not on drivers. ${ }^{21-22}$ These include two (2) workers connecting an LPG pipe under the road and a case involving an intentional act.

Sirdah and Rahma did a study in Palestine on the perceived health status of drivers of cars on auto-LPG, diesel and gasoline. Results showed that majority of drivers using diesel and gasoline reported headache, nausea and blurring of vision compared to the drivers of auto-LPG vehicles. Similarly, the Mean Health Complaint Score Percentage (MHSP) showed that auto-LPG drivers had a much smaller number of complaints than diesel and gasoline. Volatile organic compounds (VOC) measured inside the cars poorly correlate with the perceived health status of the drivers. ${ }^{6}$

In 2012, the Department of Health (DOH) in collaboration with the University of the Philippines Philippine General Hospital (UP-PGH) National Poison Management and Control Center concluded its study on Rapid Assessment for Monitoring Exposure Risks in Conventional and Alternative Fuel Use among the Public Transport Sector which involved randomly selected 26 autoLPG and 13 gasoline/diesel taxi drivers. Findings showed that more auto-LPG taxi drivers presented with medical complaints, abnormal peripheral blood smears, sulfhemoglobinemia and abnormal pulmonary function 
tests. The taxis were tested for butane, $\mathrm{CO}$, hydrogen sulphide $\left(\mathrm{H}_{2} \mathrm{~S}\right)$ for auto-LPG vehicles and volatile aromatic compounds, $\mathrm{CO}, \mathrm{H}_{2} \mathrm{~S}$ and $\mathrm{O}_{2}$ levels for gasoline/diesel taxis. Results showed that $\mathrm{CO}$ and $\mathrm{H}_{2} \mathrm{~S}$ levels in the auto-LPG taxis were much higher than in gasoline/diesel taxis. The study noted that several factors contribute to the emission of toxic chemicals in the vehicle which include inaccurate and improper conversion of vehicle to LPG, lack of regular environmental monitoring of vehicles, poor maintenance of the vehicle and long work hours spent by drivers. ${ }^{23}$

\section{Burns}

The risk of injury from ignition or explosion of LPG is well recognized. Several reports worldwide on explosions or fire causing significant burns were documented and were attributed to leaks. ${ }^{2}$

Cold burns related to auto-LPG fuel were also reported. It consists of a mixture of propane and butane which when moderately compressed turns into a liquid at atmospheric temperature and then reverts back to a gas when the pressure is sufficiently reduced. One of the dangers of autoLPG is its rapid vaporization and consequent lowering of temperature. When exposed, skin contact with the depressurized, evaporating LPG can cause severe cold burn or frostbite. ${ }^{24}$ Human errors are implicated as the most common cause of injuries. It generally involves careless fuel handling and faulty workmanship such as poor sealing of bodywork around remote refueling connectors. Some of the patients sustained injuries related to refueling process with one case report involving smoking. Technical malfunctions were also implicated such as weakening of the tank wall, crashes resulting in an impact to the tank and leakage from the tank were also reported. . $^{13,24-27}$

\section{Discussion and Conclusion}

The data available on auto-LPG and its impact on health mainly involved instantaneous exposure to high levels causing acute injuries and even death. Limited studies are available about the chronic effects of auto-LPG fuel during prolonged exposure to relatively small amounts in situations of undetected leaks. This is mainly due to 1) no significant reports on the negative health effects with the use of autoLPG in other countries; 2) the difficulty in measuring health outcomes in relation to auto-LPG use in the presence of other factors such as smoking, outdoor air pollution, overall condition of the vehicle and unsafe work practices. The development and use of objective assessments of health outcomes (e.g. clinical and laboratory examinations) and presence of auto-LPG in the vehicle through environmental monitoring are necessary to make relevant correlations.

The DOH study showed that auto-LPG taxi drivers presented with more medical complaints as well as higher levels of toxic gases found in auto-LPG units. There have been no reports of health complaints with the use of auto-
LPG in other countries. This difference can be due to the existence and strict implementation of regulations based on standard guidelines on the use of auto-LPG in other countries. Leaks in auto-LPG taxis are caused by inaccurate and improper conversion of vehicle to auto-LPG, lack of regular environmental monitoring of vehicles and poor maintenance of the vehicles. Regulations governing autoLPG use should be reviewed and amended to include strict implementation of standard and authorized conversion of vehicles; safety training of operators and drivers to prevent exposure; information campaign regarding auto-LPG to reassure the public; occupational health and safety program for drivers to address other health hazards; strict air quality testing to determine adequate oxygen level ventilation and chemical contaminants in the vehicle during annual registration and spot checks; establishment of regulatory standards on the permissible level of odorants that can be added to auto-LPG and notification of illnesses related to its use. Other recommendations are strict observation of maintenance schedule and implementation of realistic work schedules for drivers. The regulations should be formulated and implemented with the support of auto-LPG industry organizations, taxi operators, refueling stations and drivers to promote health and safety with the use of auto-LPG.

\section{References}

1. United Nations University International Conference, Maastricht, The Netherlands, An Overview of Alternative Transport Fuels in Developing Countries: Drivers, Status and Factors Influencing Market Deployment [Online]. 2005 [cited 2012 Aug]. Available from http://www.intech.unu.edu/events/workshops/hfc05/Papers/Boyle.pdf.

2. Hong Kong Research and Library Services Division Legislative Council Secretariat, A Study on LPG as a Fuel for Vehicles [Online]. 1997 [cited 2012 Aug]. Available from http://sc.legco.gov.hk/sc/www.legco.gov.hk/ yr97-98/english/sec/library/967rp05.pdf.

3. Chang CC, Lo JG, Wang JK. Assessment of reducing ozone forming potential for vehicles using LPG as an alternative fuel. Atmos Environ. 2001; 35(35):6201-11.

4. Gamas E, Diaz L, Rodriguez R, et al. Exhaust emissions from gasolineand LPG-powered vehicles operating at the altitude of Mexico City. J Air Waste Manag Assoc. 1999; 49(10):1179-89.

5. Department of Energy Portal, Oil Price Monitor [Online]. [cited 2012 Sept]. Available from http://www.doe.gov.ph/OPM/Oilmonitor.htm

6. Sirdah, M,Rahma, M. Health Consequences of Using Liquefied Petroleum Gas (LPG) as an Alternative Car Fuel in Gaza Governates. International Journal of Health Research. 2010; 3(1): 37-44.

7. Higgins G. An Assessment of Propane as a Transportation Fuel for Light-Duty Fleets in Canada. A Preliminary Report [Online]. 2008 [cited 2012 Aug]. Available from http://mx1.www.edproenergy.com/upload/ reports/preliminaryreport.pdf.

8. World LP Gas Association, Autogas Incentive Policies: A country-bycountry analysis of why and how governments promote Autogas and what works [Online]. 2012 [cited 2012 Aug]. Available from http://www.worldlpgas.com/uploads/Autogas_Incentive_Policies_2012. pdf

9. Department of Energy Portal, Sec. JRD Almendras' Presentation: Energy Forum: Clark, Pampanga, Philippines [Online]. 2012 [cited 2012 Aug]. Available from http://www.doe.gov.ph/Sec\%20Corner/ SRDA\%20Energy\%20Sector\%20-\%20Clark.pdf. 
10. Philippine Daily Inquirer. Drivers, passengers say something's very wrong with LPG-fueled taxis [Online]. 2011 [cited 2012 Aug]. Available from http://newsinfo.inquirer.net/87255/drivers-passengers-saysomething\%E2\%80\%99s-very-wrong-with-lpg-fueled-taxis.

11. World LP Gas Association, LPG Exceptional Energy: History of LPG [Online]. 2012 [cited 2012 Aug]. Available from http://www.exceptionalenergy.com/en_GB/what-is-lpg/history.

12. Wright TC, Kim JB, Curie LJ, Kay AR, Burge TS. Leakage of Liquefied Petroleum Gas during motor vehicle refueling - a new cause of cold injury. Burns. 2006; 32(1):132-3.

13. Demirbas A. Fuel Properties of Hydrogen, Liquefied Petroleum Gas (LPG), and Compressed Natural Gas (CNG) for Transportation. Energy Sources. 2002; 24(7):601-10.

14. World Health Organization, Global Health Observatory Outdoor Air Pollution [Online]. 2012 [cited 2012 Aug]. Available from http://www.who.int/gho/phe/outdoor_air_pollution/en/index.html.

15. Singh A, Gangopadhyay S, Nanda PK, Bhattacharya S, Sharma C, Bhan C. Trends of greenhouse gas emissions from the road transport sector in India. Sci Total Environ. 2008; 390(1):124-31.

16. Schifter I, Díaz L, López-Salinas E, Rodríguez R, Avalos S, Guerrero V. An evaluation of the LPG vehicles program in the Metropolitan Area of Mexico City. J Air Waste Manag Assoc. 2000; 50(2):301-9.

17. Ristovski ZD, Jayaratne ER, Morawska L, Ayoko GA, Lim M. Particle and carbon dioxide emissions from passenger vehicles operating on unleaded petrol and LPG fuel. Sci Total Environ. 2005; 345(1-3):93-8.

18. Gasca J, Ortiz E, Castillo H. The impact of LPG usage on air quality in Mexico City. Atmos Environ. 2004; 38:3517-27.
19. Center for Disease Control and Prevention, NIOSH Pocket Guide to Chemical Hazards:LPG [Online]. 2011 [cited 2012 Aug]. Available from http://www.cdc.gov/niosh/npg/npgd0679.html.

20. Roberge B. Evaluation and control of carbon monoxide exposure from propane-fueled forklifts. Appl Occup Environ Hyg. 1998; 13(3):183-91.

21. Sugiea H, Sasakia C, Hashimoto C, et al. Three cases of sudden death due to butane or propane gas inhalation: analysis of tissues for gas components. Forensic Sci Int. 2004; 143(2-3):211-4.

22. Fukunaga $\mathrm{T}$, Yamamoto $\mathrm{H}$, Tanegashima A, Yamamoto $\mathrm{Y}$, Nishi $\mathrm{K}$. Liquefied petroleum gas (LPG) poisoning: report of two cases and review of the literature. Forensic Sci Int. 1996; 82(3):193-200.

23. Rapid Assessment for Monitoring Exposure Risks in Conventional and Alternative Fuel Use among the Public Transport Sector. Department of Health; UPM-National Poison Management and Control Center. 2012.

24. Scarr B, Mitra B, Maini A, Cleland H. Liquefied petroleum gas cold burn sustained while refueling a car. Emerg Med Australas. 2010; 22(1):82-4.

25. Bozkurt M, Kulahci Y, Zor F, Kapi E. Burn injuries related to LPG gaspowered cars. J Burn Care Res. 2008; 29(6):897-901.

26. Knobloch K, Ipaktchi R, Rennekampff HO, Vogt PM. Hand and facial burns related to liquefied petroleum gas (LPG) refuelling and cigarette smoking--an underestimated risk? Burns. 2010; 36(7):140-2.

27. Seyhan N, Jasharllari L, Kayapınar M, Savacı N. An unusual cause of cold injury: liquified petroleum gas leakage. Ulus Travma Acil Cerrahi Derg. 2011; 17 (6):561-2.

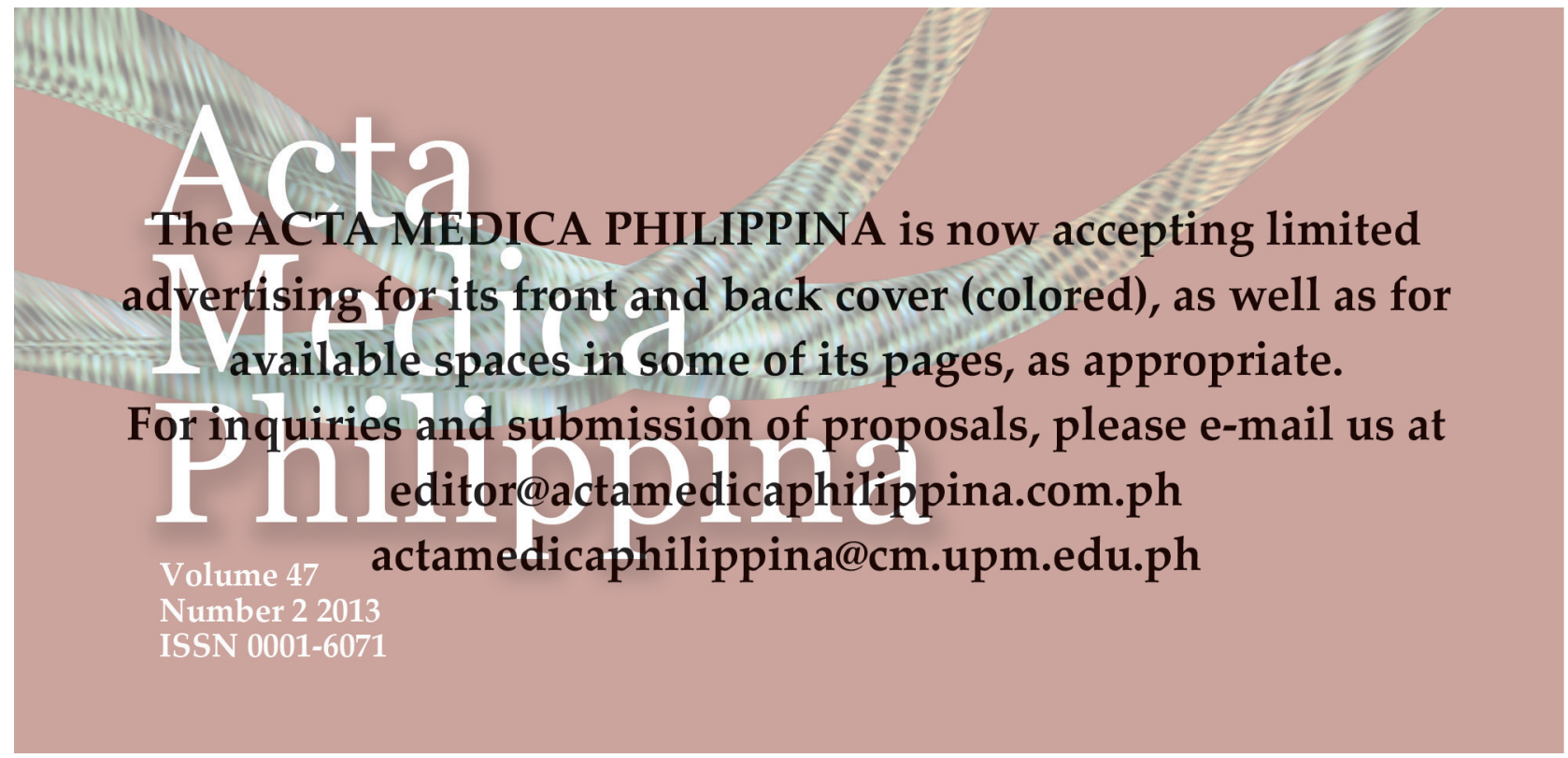

